report

\title{
Basic Clinical Radiobiology Course Ljubljana (Slovenia), 21.-25. May 2006 View from a local participant
}

As the course took place in Slovenia, I should first of all tell a couple of words about my country and its capital Ljubljana. Slovenia is a small country with only two million people, but it has all that one needs to enjoy life: the sea, mountains, some beautiful lakes and Karst landscapes with a lot of natural caves. Add to this some very good wines and food delights - but you should really find out first hand. Ljubljana is a city of cultural and rich historical heritage. It is similar to other Central European cities. Some compare it to Vienna or Prague, but its particular charm lies in the smallness of this town, with the total population of only around 300.000 people.

The course started on Sunday, the $21^{\text {st }}$ of May with the introduction to radiobiology. In the afternoon, after the coffee break, the participants could attend the tutorials of "basic" or "advanced knowledge" of radiobiology. I suppose people who work in radiotherapy must be modest, since most participants chose the "basic knowledge" group. Even if the group was supposed to be "basic", the discussions were not. During the first day, as well as during the following days, we discussed some very interesting topics like re-radiation, modifiers of late complications, $\alpha / \beta$ ratio in prostate cancer and whether or not to give the same treatment for the whole course of radiotherapy. We also touched upon the eventual connection between IMRT and secondary tumors. The second day started with a lecture about radiobiology of normal tissues and continued with an explanation of the role of checkpoints in the cells. The next lecture emphasized the importance of proper documenting. The day continued with a presentation of the linear quadratic model, followed by a lecture about hyperfractionation. During the third day, the issues of oxygenation in radiotherapy, of mathematical models and of combination of radiotherapy with chemotherapy were discussed. The following day when the participants were confronted with the problems of using such models in practice, all the enthusiasm about models faded away. It became obvious that, unfortunately, models do not always work well in practice. The next topic on the agenda was biological image-guided radiotherapy, and in the afternoon, the combination of new biological therapies with radiotherapy was presented.

Tuesday was the so called "social day". The participants first took a trip to the beautiful lake of Bled, and in the evening, they were invited to dinner. The atmosphere was excellent, just right to meet other people and make new acquaintances. The participants had a great time - but how could it have been otherwise with such great lecturers and participants. They came from all around the world, from exactly eighteen countries. During the evening two new members of the "radiobiology" team were presented to us, the new lecturer Dr. Susan Short and the new organizer Mrs. Viviane Van Egten.

One of the standard features of such events is the poor quality of the coffee served during the breaks. Surprisingly, during this course, the coffee was really good and one of the lecturers even said that this was the best coffee he had ever had at any course. However, this course will not be remembered because of the coffee, but rather for excellent lectures and teachers. Thanks to them, the course was really good. The participants had the chance to learn a lot and were challenged to use this knowledge in everyday practice. Special thanks go to the course director Professor Van der Kogel for the excellent scientific program. And to all of you, hope to see you next time in Ljubljana.

Mirjana Rajer, MD

Institute of Oncology Ljubljana

Ljubljana, Slovenia 